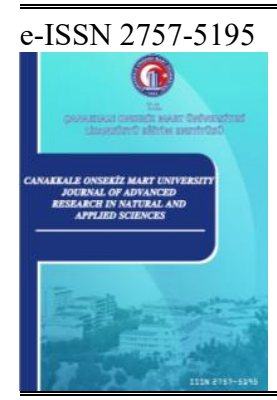

Çanakkale Onsekiz Mart University

Journal of Advanced Research in Natural and Applied Sciences

Open Access

\title{
Gelibolu Yarımadası Savaş Arkeojeofiziği Çalışmaları: Şahindere Şehitliği ve Lone Pine Anıtı Örnek Bölgeleri
}

\author{
Cahit Çağlar Yalçıner ${ }^{1 *}$, Yunus Can Kurban², Erdem Gündoğdu ${ }^{1}$, Mehmet Ali Yücel ${ }^{3}$ \\ ${ }^{1}$ Madencilik ve Maden Çıkarma Bölümü, Çan Meslek Yüksekokulu, Çanakkale Onsekiz Mart Üniversitesi, Çanakkale, Türkiye \\ ${ }^{2}$ Jeoloji Mühendisliği Bölümü, Eskișehir Osmangazi Üniversitesi, Eskișehir, Türkiye \\ ${ }^{3}$ Harita Mühendisliği Bölümü, Mühendislik Fakültesi, Çanakkale Onsekiz Mart Üniversitesi, Çanakkale, Türkiye
}

\begin{abstract}
Makale Tarihçesi
Gönderim: $\quad 05.04 .2021$

Kabul: $\quad 21.06 .2021$

Yayım: $\quad 20.09 .2021$

Araştırma Makalesi

Öz - Çanakkale Savaşı (Çanakkale Muharebeleri), I. Dünya Savaşı sırasında 1915-1916 yılları arasında Gelibolu Yarımadası'nda Osmanlı İmparatorluğu ile İtilaf Devletleri arasında yapılan deniz ve kara muharebeleridir. Dünyanın en kanlı ve yoğun çarpışmalarının yaşandığı cephelerde, özellikle İtilaf Devletlerinin kayıpları ile beraber geri çekilme süreçlerinde mühimmat ve teçhizatlarını yanlarına almadan gerek gömerek gerekse tahrip ederek arkalarında bırakmışlardır. Gelișen teknolojik yenilikler sayesinde yeraltında gömülü durumda bulunan obje ya da kalıntılar, planlanan bölgelerde yapılan jeofizik, jeodezik ve uzaktan algılama çalışmaları ile belirlenmiştir. Çalışma kapsamında ilk olarak; tüm alanlarda İHA görüntüleri yardımıyla sayısal yükseklik modeli oluşturulmuş ve ortofotolar üzerinden yer belirleme çalışmaları yapılmıştır. Yerden, gözle belirlenemeyen siper ve çukur gibi birçok unsur bu model sayesinde belirlenmiştir. Ayrıca İHA görüntüleri, yüksek hassasiyetli GPS ile uygulanan yeraltı radarı (GPR) ölçümlerinde de altlık olarak kullanılmıștır. Çalışma kapsamında araştırma bölgeleri Şahindere Şehitliği ve Lone Pine Anıtı çevresi olarak seçilerek jeofizik, jeodezik ve uzaktan algılama-insansız hava aracı (ïHA) uygulamaları yapılmıştır. Şahindere Şehitliğindeki ölçümler ile şehitlik alanın bilinen halinden çok daha geniş olduğu belirlenmiştir. Lone Pine bölgesinde yapılan ölçümler ile siper hatlarıı birbirine bağlayan tünel yerleri tam olarak haritalanmıştır. Bu kapsamda yapılan ilk ayrıntılı çalışma olan bu uygulama; hem bilinen verilere büyük katkı sağlamış, hem ileride yapılacak çalışmalara yön verecek bulgular sağlamıştır.
\end{abstract}

\section{Gallipoli Peninsula War Archeogeophysics Studies: Şahindere Martyrdom and Lone Pine Monument Sample Study Sites}

\footnotetext{
${ }^{1}$ Department of Mining and Mineral Extraction, Çan Vocational School, Çanakkale Onsekiz Mart University, Çanakkale, Turkey

${ }^{2}$ Department of Geology Engineering, Eskişehir Osmangazi University, Eskişehir, Turkey

${ }^{3}$ Department of Geomatics Engineering, Faculty of Engineering, Çanakkale Onsekiz Mart University, Çanakkale, Turkey
}

Article History

Received: $\quad 05.04 .2021$

Accepted: $\quad 21.06 .2021$

Published: $\quad 20.09 .2021$

Research Article

\begin{abstract}
The Dardanelles Battle were sea and land battles between the Ottoman Empire and the Entente States during the WW1 between 1915-1916 on the Gallipoli Peninsula. On the fronts where the world's most bloody and intense battles were experienced, especially in the withdrawal processes of the Entente States, they left behind both burying and destroying the ammunition and equipment without taking them with them. Due to the technological innovations, the determination of the objects or remains buried underground was determined by geophysical, geodetic and remote sensing studies in the determined regions. Within the scope of the study first, a digital elevation model of study areas was created with the help of UAV images and location studies were carried out on orthophotos. Many elements such as trenches and pits that cannot be detected from the ground have been determined by this model. In addition, UAV images were also used as a base for Ground Penetrating Radar (GPR) measurements applied with high-sensitivity GPS. In this study, the research areas were selected as, Şahindere Martyrdom and Lone Pine Monument area, and geophysical, geodetic, remote sensing-UAV applications were completed. With the measurements in the Şahindere Martyrdom, it was determined that the martyr area was much wider than the current state. The measurements made at the Lone Pine site and the tunnel locations connecting the trench lines were clearly mapped. This is the first detailed study in this context, which has contributed greatly to the current data and provided findings that will guide future studies.
\end{abstract}

Keywords - Archaeogeophysics, Gallipoli peninsula, war remnants, martyrdom, ground penetrating radar (GPR)

\footnotetext{
1 (1D) yalciner@comu.edu.tr*

2 (D) ykurban@gmail.com

3 (1D) erdem@comu.edu.tr

4 (D) aliyucel@comu.edu.tr

*Sorumlu Yazar / Corresponding Author
} 


\section{Giriş}

Çanakkale savaşlarında gerek alanın genişliği gerekse savaşın şiddetine bir de süre bakımından oldukça kısa zamanda gerçekleşmesi eklendiğinde hem şehitlik alanların yerlerinin hem de savaş kalıntıların yerlerinin tam bilinmemesi normaldir. Bu doğrultuda önceki çalışmalar sı̆̆ jeofizik yöntemlerdeki gelişmelerin yeraltında gömülü durumda bulunan yapısal unsurların (mezar, top, mühimmat gibi) ortaya çıkarılmasında ve İHA çalışmalarının ise siperlerin belirlenmesini kolaylaştırdığı görülmektedir (Büyüksaraç, Bektaș, Tulunay, ve Ateș, A., 2013; Büyüksaraç vd. 2014; Yalçıner, 2012; Yücel, Yücel, Yalçıner, ve Y1lmaz, 2018).

Çanakkale savaşlarında kaybettiğimiz şehitlerimizin naaşlarının yerlerinin belirlenmesi ve aradan geçen 103 yıl sonra bile gereken saygıya kavuşmaları için gereken çalışmaları yapmak bu çalışmadaki en önemli amaç olmuştur. Çalışma alanının tüm cephelere yönelik olmasının gerek zaman gerekse sonuçların yorumlanması açısından etkin olmayacağı açıktır. Bu doğrultuda çalışmaların ilk aşaması olarak saha belirleme ve gözlemlerin yapılarak doğru noktaların belirlenmesi büyük önem taşımaktadır. Özellikle İtilaf devletlerinin kara harekâtına yönelik çıkartma yaptığı sahil kesimleri öncelikli olmuştur (Şekil 1). Bununla beraber yerleri kesin olarak belli olmayan şehitlik alanları da hem jeofizik yöntemler ile araştırılacak hem de yüzeydeki durumları insansız hava aracı (IHH) yardımı ile haritalanmıştır.

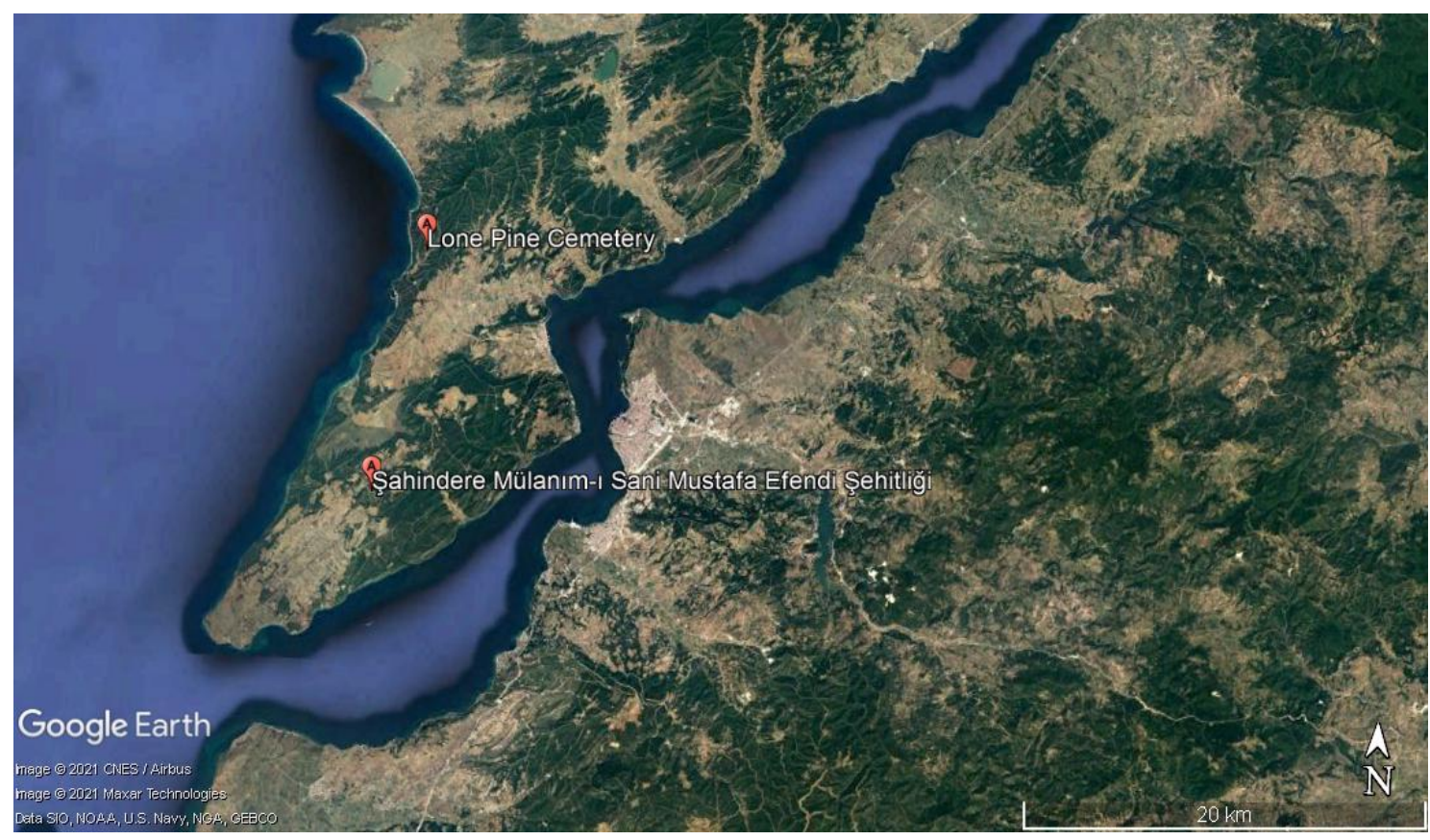

Şekil 1. Google Earth görüntüsü üzerinde çalışma alanlarının gösterimi

\section{Materyal ve Yöntem}

Çalışmanın başlangıcında literatür ve ofis çalışmaları 1şığında belirlenen bölgeler üzerinde jeolojik ve jeomorfolojik gözlemler yapılmıştır. Hava ve uydu fotoğraflarının, topografik haritalar ile karşılaştırılması ile arazinin ayrıntılı topoğrafyası sayısal olarak oluşturulmuştur. Buna destek olarak İHA ile uygulanan fotogrametrik çalışmalar ile ölçüm sahalarının yüksek çözünürlüklü sayısal yükseklik modeli ve ortofotosu oluşturulmuştur. $\mathrm{Bu}$ sayede uygulanacak olan jeofizik ölçümlerin yerleri tam olarak sayısal ortamda da işlenmiştir.

Yeraltı radarı yönteminde (GPR); yatay doğrultuda yere uygulanan birçok jeofizik yöntem, son yıllarda yapılarda da etkili şekilde uygulanmaktadır. Özellikle hasar vermeden inceleme gerektiren tarihi binalarda oldukça önemli bir üstünlük sağlanmaktadır. Farklı jeofizik yöntemlerin birçok tarihi bina inceleme projesinde başarıyla uygulanmasına karşın, en etkili yöntemin yeraltı radarı yöntemi (GPR) olduğu çoğu uygulayıcı 
tarafından kabul görmektedir. Yeraltı radarı, arkeolojik alanlarda ve kültürel miras araştırmalarında oldukça etkili ve yaygın şekilde kullanılan bir jeofizik yöntemdir (Martínez-Garrido, Fort, Gómez-Heras, Valles-Iriso, ve Varas-Muriel, 2018; Johnston, Ruffell, McKinley, ve Warke, 2018; Yalçıner, Kurban, ve Altınel, 2017; Yalçıner, Büyüksaraç, ve Kurban, 2019). Yeraltı radarı yöntemi (GPR), elektromanyetik sinyallerin iletimi ve daha sonra bilinen süreksizliklerin ürettiği yansımaların alınması yoluyla duvarlar ve zeminler altındaki yüzeyden görülemeyen yapıyı ortaya çıkarabilmektedir (Ming-Chih, Yu-Ming, Kun-Fa, ve Hui-Chi, 2009; Persico, Ciminale, and Matera, 2014). Yüksek frekanslı yeraltı radarı yöntemi (GPR) ölçüm düzeneği gereği var olan antenler, 1-60 ns aralığında, çok yüksek ve aşırı çok yüksek (30-3000 MHz) bandında kısa elektromanyetik sinyal gönderir. Yeraltı radarı yöntemi (GPR), tahribatsız kolay uygulanabilirliği ve yüksek hassasiyetteki yüksek çözünürlükte verdiği sonuçlar sayesinde, mühendislik jeolojisinden, çevre araştırmalarına, arkeolojik çalışmalardan, yapısal mühendislik çalışmalarına kadar birçok alanda kullanılmaktadır (Daniels, 2004). Son olarak, yine İstanbul'da Kariye Müzesi restorasyonu öncesi yaptıkları çalışmada Yalçıner vd. (2019), yeraltı radarı yöntemi (GPR) ve Ultrasonik Darbe Hızı (UPV) Testini kapsayan tahribatsız test tekniklerini kullanarak yapısal elemanların taş kalitesi, yapı içi geometrisi ve fiziksel özelliklerini yorumlamışlardır. Benzer şekilde çok sayıda çalı̧̧mada bu yöntem ile tarihi yapıların hasarsız incelemeleri yapılmıştır (Leucci, Masini, Persico, ve Soldovieri, 2011; Leucci, Masini, ve Persico, 2012; Moropoulou, Labropoulos, Delegou, Karoglou, ve Bakolas, 2013; Kanlı vd., 2015; Gil, Mas, Lerma, Torner, ve Vercher, 2019). Teknolojik gelişmeler sayesinde yüksek frekanslı antenlerin $(450 \mathrm{MHz}-2.3 \mathrm{GHz})$ kullanılması ile tarihi önem taşıyan binaların ve yapıların restorasyon çalışmalarında da vazgeçilmez bir tahribatsız araştırma yöntemi (NDT) olarak kendine yer bulmuştur (Yalçıner vd., 2019). Bu çalışmada da yeraltı radarı yöntemi tahribatsız olarak çalışma sahalarında ölçümler gerçekleştirilmiştir. Yaklaşık $6 \mathrm{~m}$ nüfuz derinliğine kadar yüksek çözünürlüklü görüntüler elde etmek için Mala marka 450 MHz HDR PRO cihazı ile hem yatay hem dikey doğrultuda uygulanan ölçümler ile taramalar gerçekleştirilmiştir (Șekil 2). Ölçümlerde kullanılan parametreler Tablo 1'de verilmiştir.

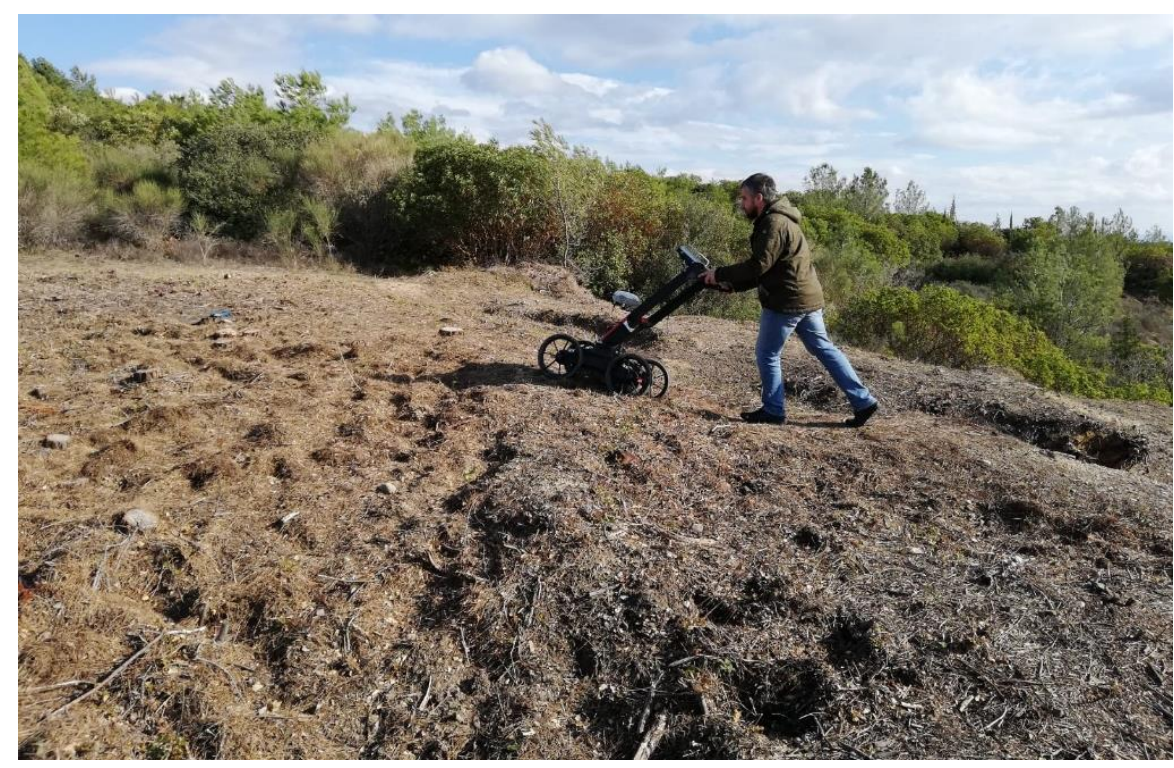

Şekil 2. Çalışmada kullanılan $450 \mathrm{MHz}$ HDR anten ile yeraltı radarı (GPR) uygulaması 
Tablo 1

Yeraltı radarı yöntemi (GPR) ile yapılan ölçümlerde kullanılan parametreler

\begin{tabular}{ll}
\hline Anten Frekans1 & $450 \mathrm{MHz}$ (HDR) \\
\hline İz Aralığ1 & $0.035 \mathrm{~m}$ \\
Örnek Sayıs1 & 512 \\
Örnekleme Frekans1 & $5120 \mathrm{MHz}$ \\
Zaman Penceresi & $114.45 \mathrm{~ns}$ \\
Profil Aralığ & $0.5 \mathrm{~m}$ \\
\hline
\end{tabular}

Yeraltı radarı profillerinin sayısal olarak yorumlanması, aslında jeoradar sinyali tarafindan üretilen parabollerin incelenmesi ve tekdüze olmayan daha yüksek yoğunluklara sahip alanların aranması işlemidir. Bu işlem tarihsel binalar altındaki yapıların yerini ve boyutlarını doğrulamak için tahribatsız araştırma yöntemi (NDT) yaklaşımı olarak ele alınmaktadır. Yapılan veri işlem sürecinde her profil için sinyal genlikleri gruplanır ve aralarında bir karşılaştırma yapılır. Daha sonra sinyalin genliğinde ilk önemli değişikliğin olduğu derinlik aranır. Yeraltı Radarı sinyalinin zayıflamasına neden olan gerekçe tanımlanır. Son olarak, sinyalin yayılım koşullarındaki değişiklikleri ölçmek için yazılım filtreleri kullanır.

\section{Saha Çalışmaları}

\section{1. Şahindere Şehitliği}

Şahindere Şehitliği Şevki Paşa haritalarında da tam olarak belirtilmiş ve günümüzde Şehitlik olarak düzenlenmiştir (SSekil 3). Çalışmalarda ilk olarak İHA görüntülerinden üretilen sahanın koordinatlı 3 boyutlu sayısal yükseklik modeli oluşturulmuştur (Şekil 4a). Daha sonra ise belirlenen 4 farklı alanda yeraltı radarı yöntemi (GPR) ile ölçümler gerçekleştirilmiştir (Șekil 4b).

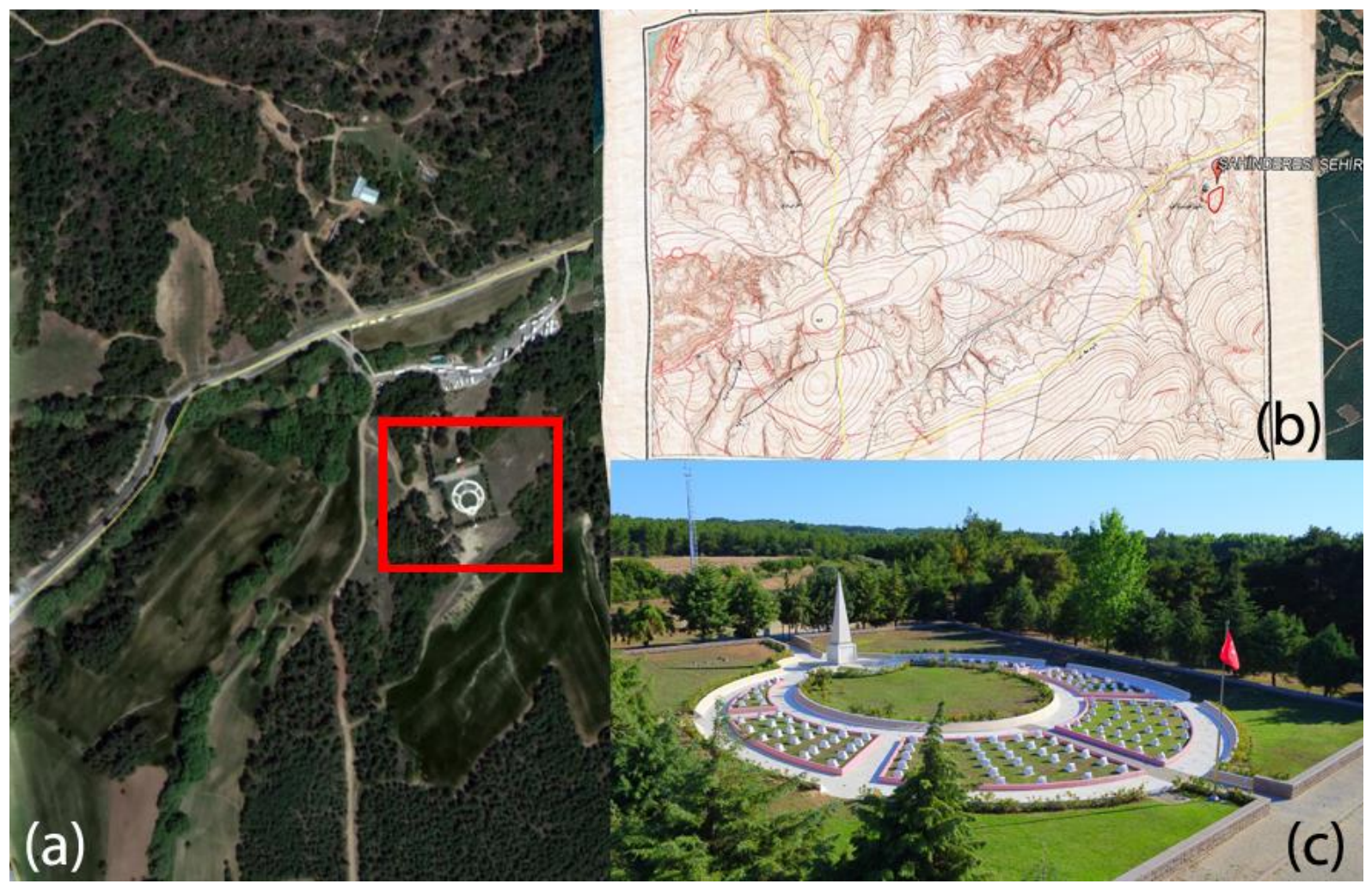

Şekil 3. Şahindere Şehitliği gösterimi.(a) Googleearth üzerinde yeri (kırmızı kutu). (b) Şevki Paşa haritasında yeri. (c) Günümüzdeki Şehitlik gösterimi. 


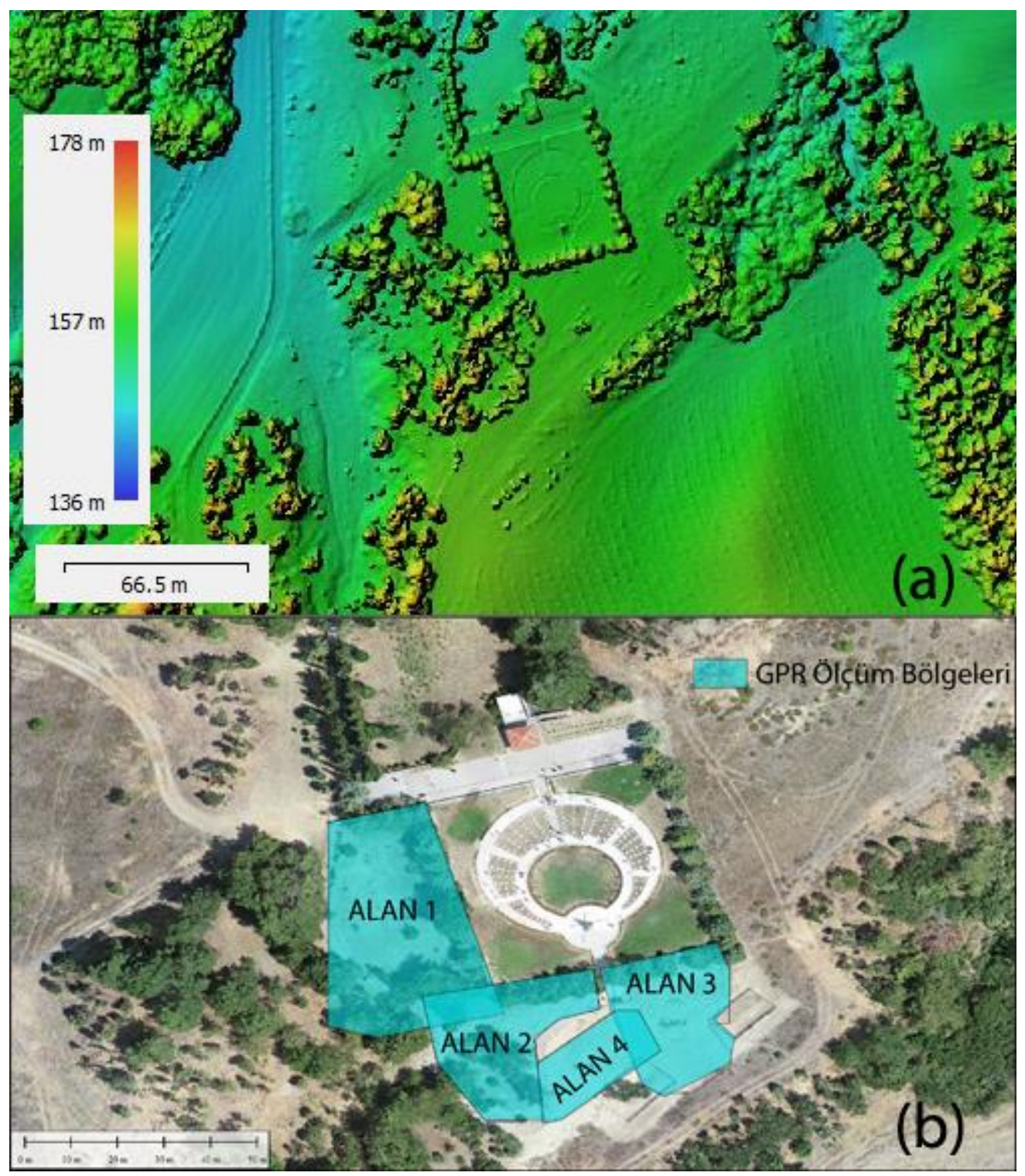

Şekil 4. UAV ile elde edilen yükseklik modeli ve yüksek çözünürlüklü ortofoto. (a) Şahindere Şehitliği çalışma alanın İHA görüntülerinden üretilen sayısal yükseklik modeli. (b) Şahindere Şehitliğinde, yeraltı radarı yönteminin (GPR) uygulandığı alanlar.

\subsection{Lone Pine}

Lone Pine, yani Yalnız Çam, ismini Avustralyalı askerlerin 25 Nisan 1915'te çıartmadan buraya geldiklerinde büyüdügünü gördükleri tek çam ağacından alıyor. Çanakkale'nin Eceabat ilçesine bağlı Kocadere Köyü sınırları içerisinde yer alan mezarlığın doğu ucunda da aynı isimle anılan bir anıt var. 25 Nisan 1915 tarihinden ağustos ayına kadar Lone Pine'de çok ağır çarpışmalar meydana gelmiş. Çalışmalarda ilk olarak İHA görüntülerinden üretilen sahanın koordinatlı 3 boyutlu sayısal yükseklik modeli oluşturulmuştur (Șekil 5). Daha sonra ise belirlenen uygun alanda, yeraltı radarı yöntemi (GPR) ile ölçümler gerçekleştirilmiştir (SSekil $\underline{5 c)}$. 


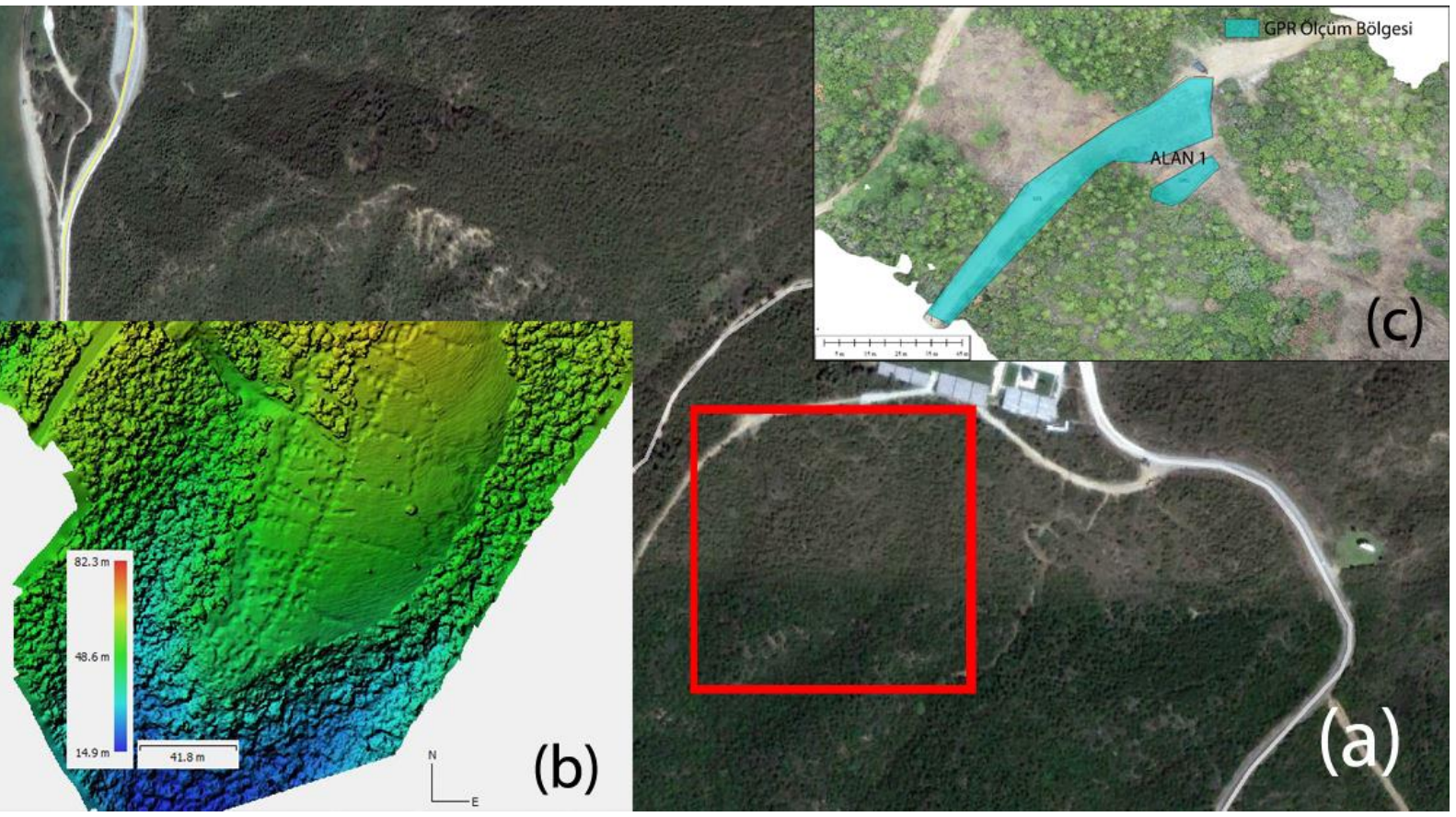

Şekil 5. Lone Pine çalışma alanın (a) GoogleEarth fotoğrafında gösterimi (kırmızı kutu). (b) İHA görüntülerinden üretilen sayısal yükseklik modeli. (c) Yeraltı radarı yönetimin (GPR) uygulandığı alanlar.

\section{Bulgular}

Çalışma yapılan bölgelerde toplanan veriler işlenerek 3 boyutlu hacimsel veri haline dönüştürülmüştür (S Sekil 6). Bu verilerin 3 boyutlu hale getirilmesi sayesinde ayrıntılı derinlik gösterimleri kat haritası olarak da hazırlanmış (Șekil 7) ve en iyi temsil eden derinlikler belirlenerek yorumlamada kullanılmıştır (Șekil 8).

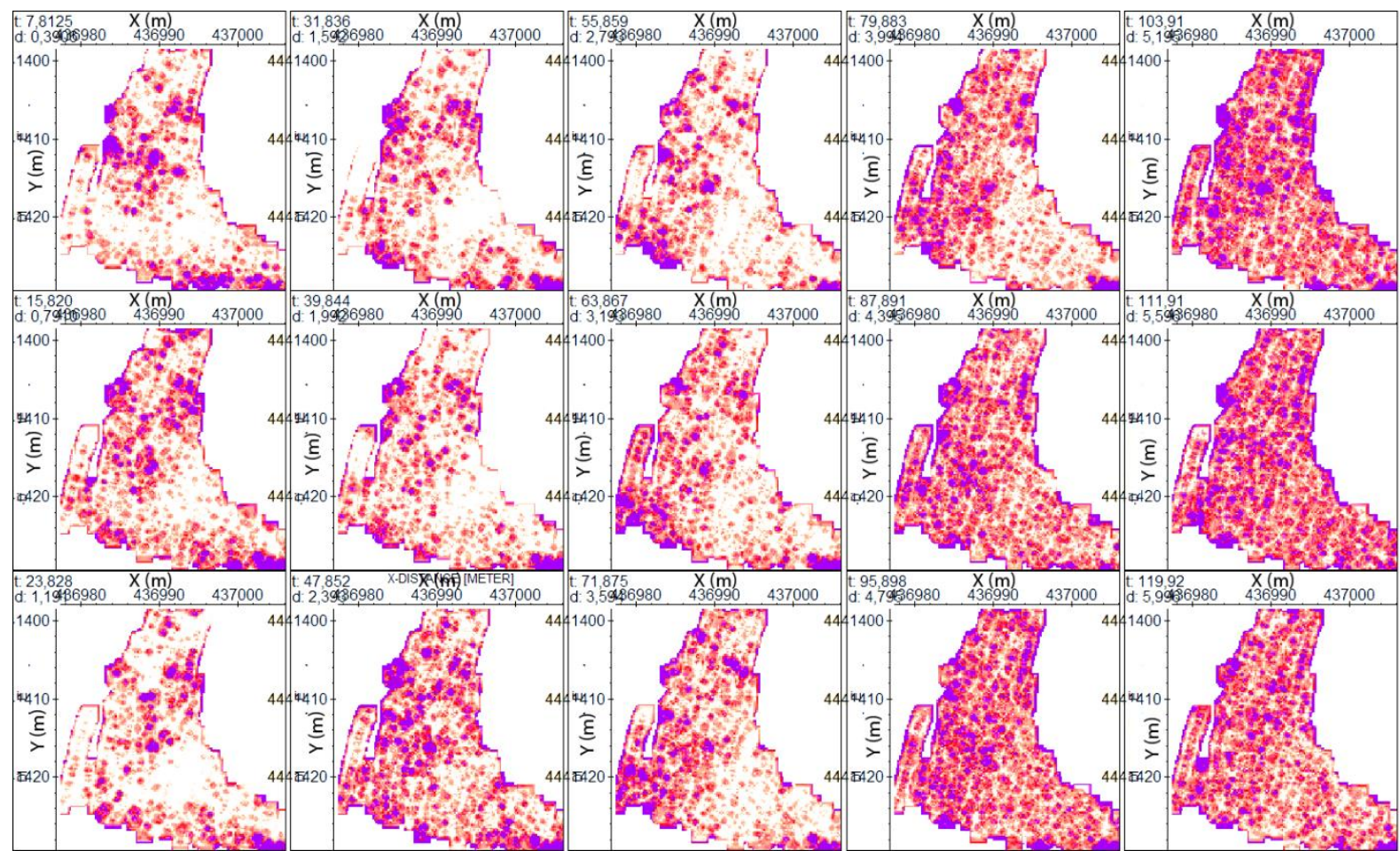

Şekil 6. Şahindere Şehitliği çalıșma bölgesi Alan 2'de elde edilen yeraltı radarı (GPR) verilerinin tüm derinliklerde gösterimi (koyu renkli alanlar belirtilere karşılık gelmektedir). 


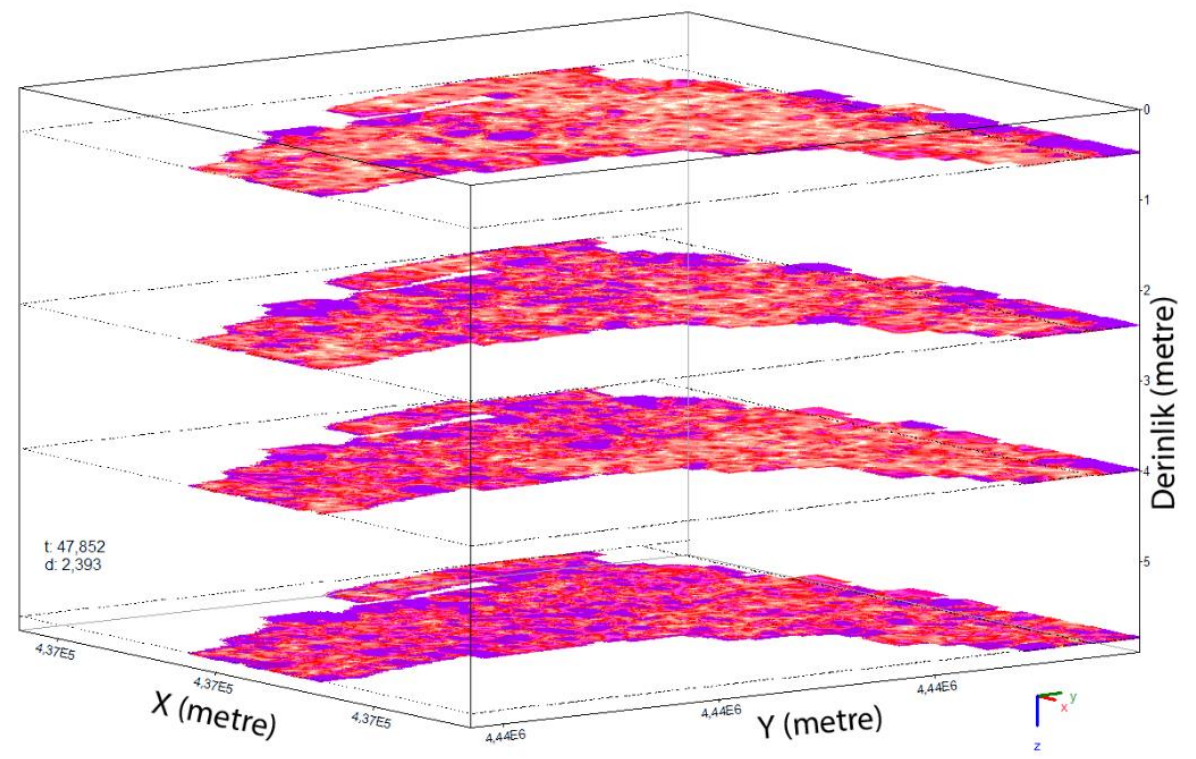

Şekil 7. Şahindere Şehitliği çalışma bölgesi Alan 2'de elde edilen yeraltı radarı (GPR) verilerinin derinlik kesitlerinin gösterimi (koyu renkli alanlar belirtilere karş1lık gelmektedir).

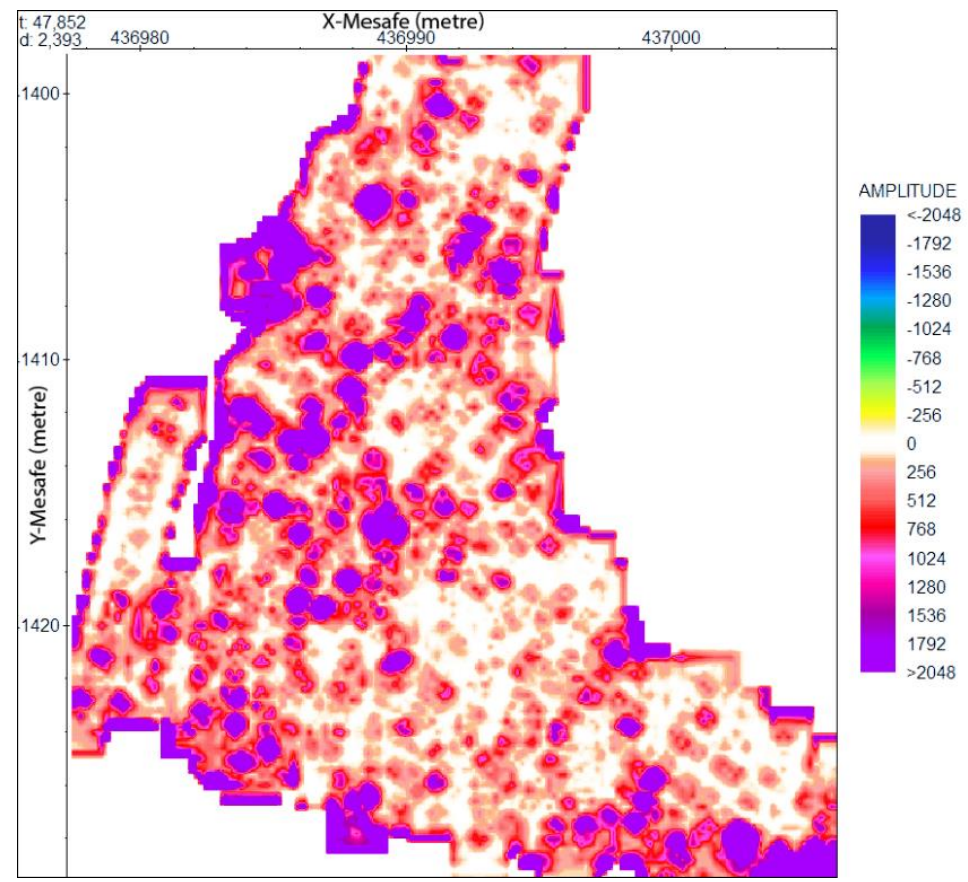

Şekil 8. Şahindere Şehitliği çalışma bölgesi Alan 2'de elde edilen yeraltı radarı (GPR) verilerinin en iyi derinlik olan $240 \mathrm{~cm}$ derinlik gösterimi (koyu renkli alanlar belirtilere karşıllk gelmektedir). 


\section{1. Şahindere Şehitliği}

Şahindere Şehitliği çalışmaları 4 bölgede uygun yerler seçilerek gerçekleştirilmiştir (Șekil 4). Alanlar İHA görüntülerinden hazırlanan ayrıntılı ortofoto üzerine incelenen 4 ayrı bölgenin genel olarak en iyi belirtiyi temsil eden derinlik seçilerek yerleştirilmiş ve yoruma hazırlanmıştır (Șekil 9).

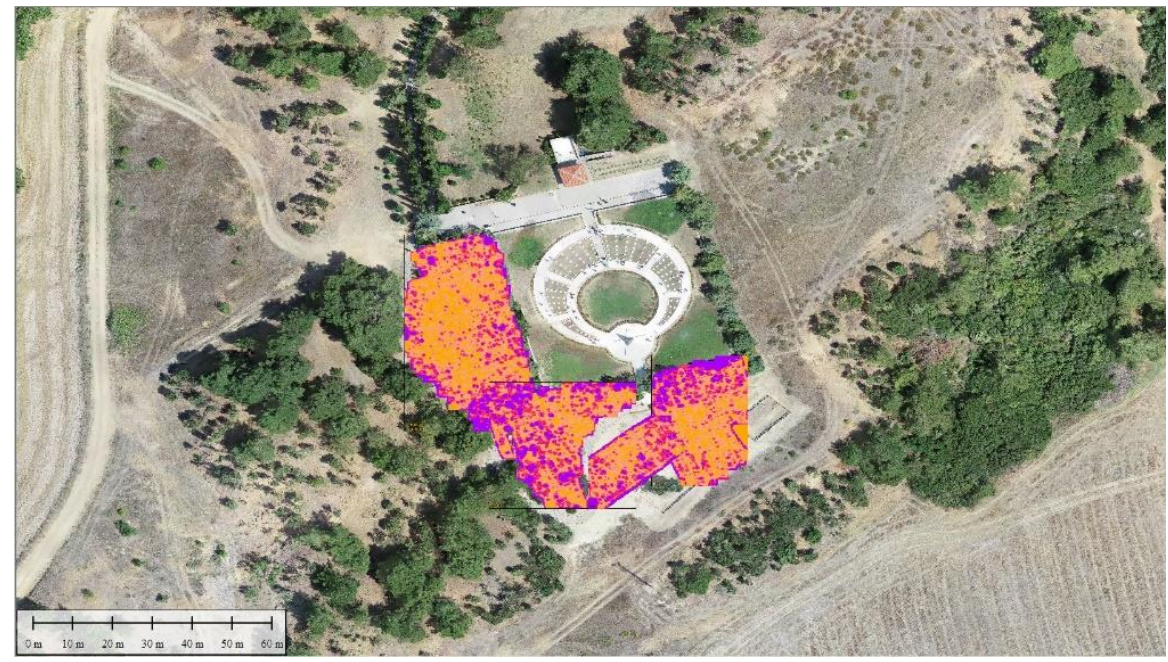

Şekil 9. Şahindere Şehitliği çalışma alanında uygulanan yeraltı radarına (GPR) ait sonuçlar (koyu renkli alanlar belirtilere karşılık gelmektedir).

Şahindere Şehitliği çevresinde yapılan çalışmalar tüm alanlarda olduğu gibi İHA uçuşları ile başlamış ve günümüzdeki şehitlik içerisini kapsamayacak şekilde en uygun olan 4 ayrı alanda gerçekleştirilmiştir (Şekil $\underline{4 b}$. Ölçüm yapılan her alanda "Olası Şehitlik" diye tanımlanabilecek belirtiler yaklaşık $240 \mathrm{~cm}$ derinlikte karşımıza çıkmıştır (Şekil 10). Normalde mezar için fazla olan bu derinliğin çevre düzenlemesi yapılmış alanda olası bir değer olduğu anlaşılmıştır. Bölgede yapılan ölçümler sonucu belirlenen olası Şehitlik alanları belirti olarak birbirlerine çok yakın olduğu için sayı vermekten kaçınılmıştır. Alan olarak yaklaşık $1130 \mathrm{~m}^{2}$ hesaplanmış bu da toplam ölçüm alanın yaklaşık $2300 \mathrm{~m}^{2}$ olduğu için \%50'sine karşılık gelmektedir. Kaba bir hesap ile mezarların $2 \mathrm{~m}^{2}$ civarında bir alan kapladığı düşünüldüğünde ise yaklaşık 500 - 550 olası Şehit Mezarı olma ihtimali bulunmaktadır. 


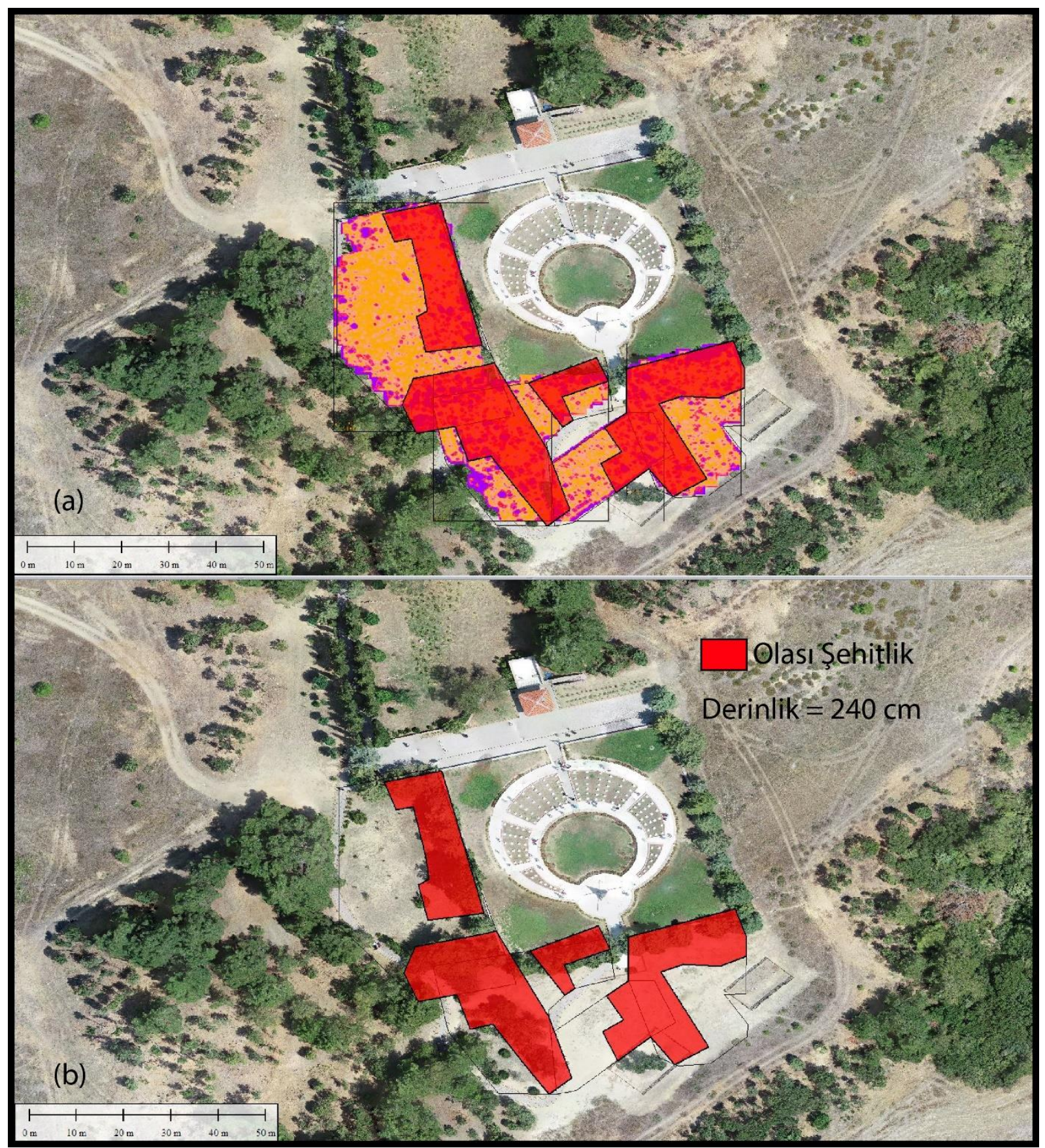

Şekil 10. Şahindere Şehitliği ölçüm bölgesinde elde edilen sonuçların gösterimi. (a) Yeraltı radarı (GPR) ile elde edilen verilerin üzerine belirtilerin yerleştirilmiş görüntüsü. (b) Belirlenen bulguların ortofoto üzerinde gösterimi.

\subsection{Lone Pine}

Lone Pine çalışma alanında İHA ölçümleri sonrasında yaklaşı $1100 \mathrm{~m}^{2}$ 'lik bir alanda yeraltı radarı (GPR) ölçümleri devam etmiştir (Șekil 5c). Yapılan ölçümlerin gösterimi için derinlik haritası oluşturulmuştur (Şekil 11). Bu derinliklerin daha iyi tanımlanabilmesi için derinlik kesiti haritası oluşturulmuştur (Şekil 12). Elde edilen derinlik haritasında asıl yapısal unsurların $150 \mathrm{~cm}$ derinde olduğu görülmüştür (Șekil 13). En iyi temsil ettiği düşünülen $150 \mathrm{~cm}$ derinlikteki yapısal unsur İHA görüntülerinden oluşturulmuş yükssek çözünürlüklü ortofoto ile çakıştırılarak belirtilerin tam yeri ortaya çıkarılmıştır (Şekil 14). 


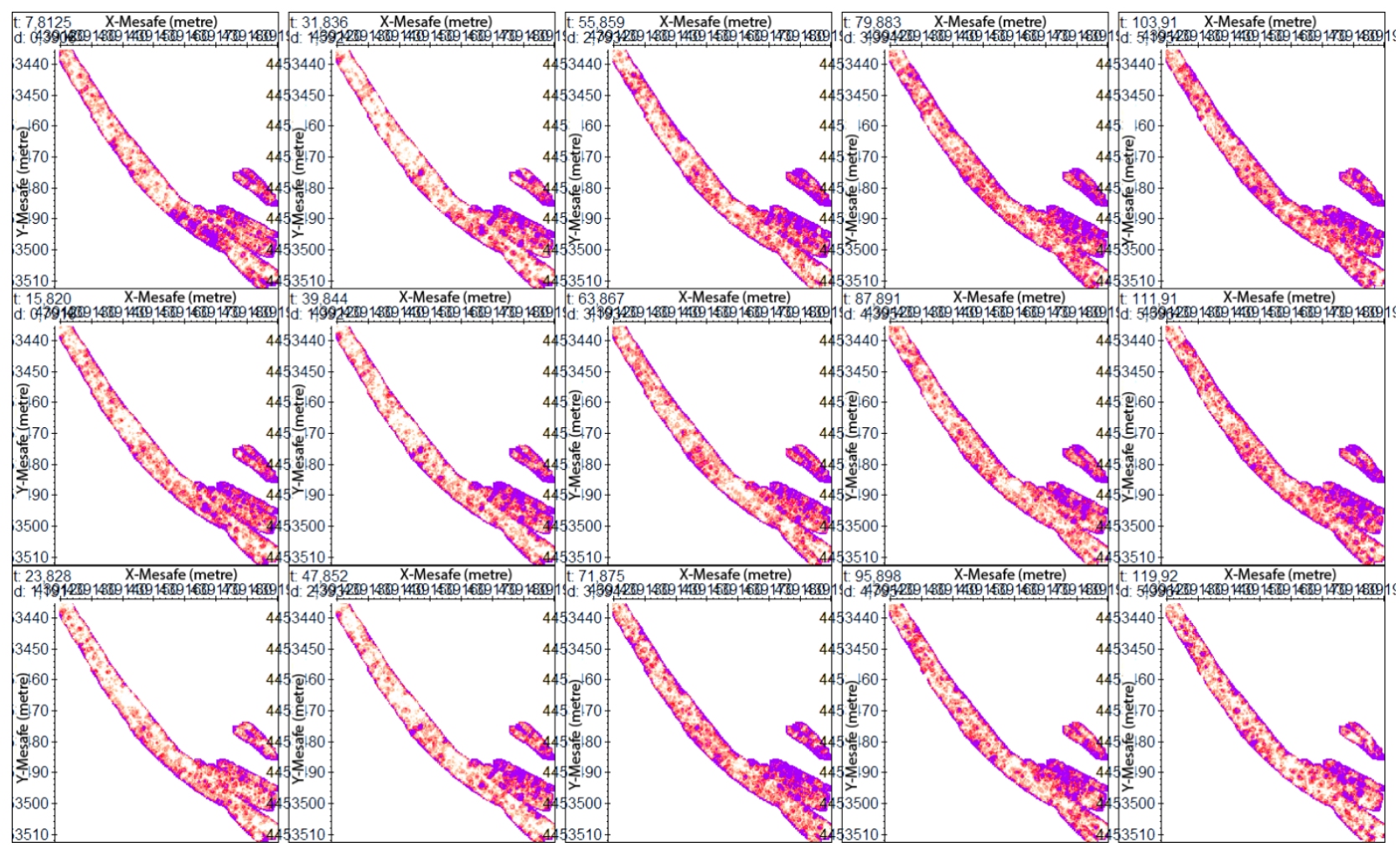

Şekil 11. Lone Pine çalışma alanında elde edilen yeraltı radarına (GPR) ait verilerin tüm derinliklerde gösterimi (koyu renkli alanlar belirtilere karş1lık gelmektedir).

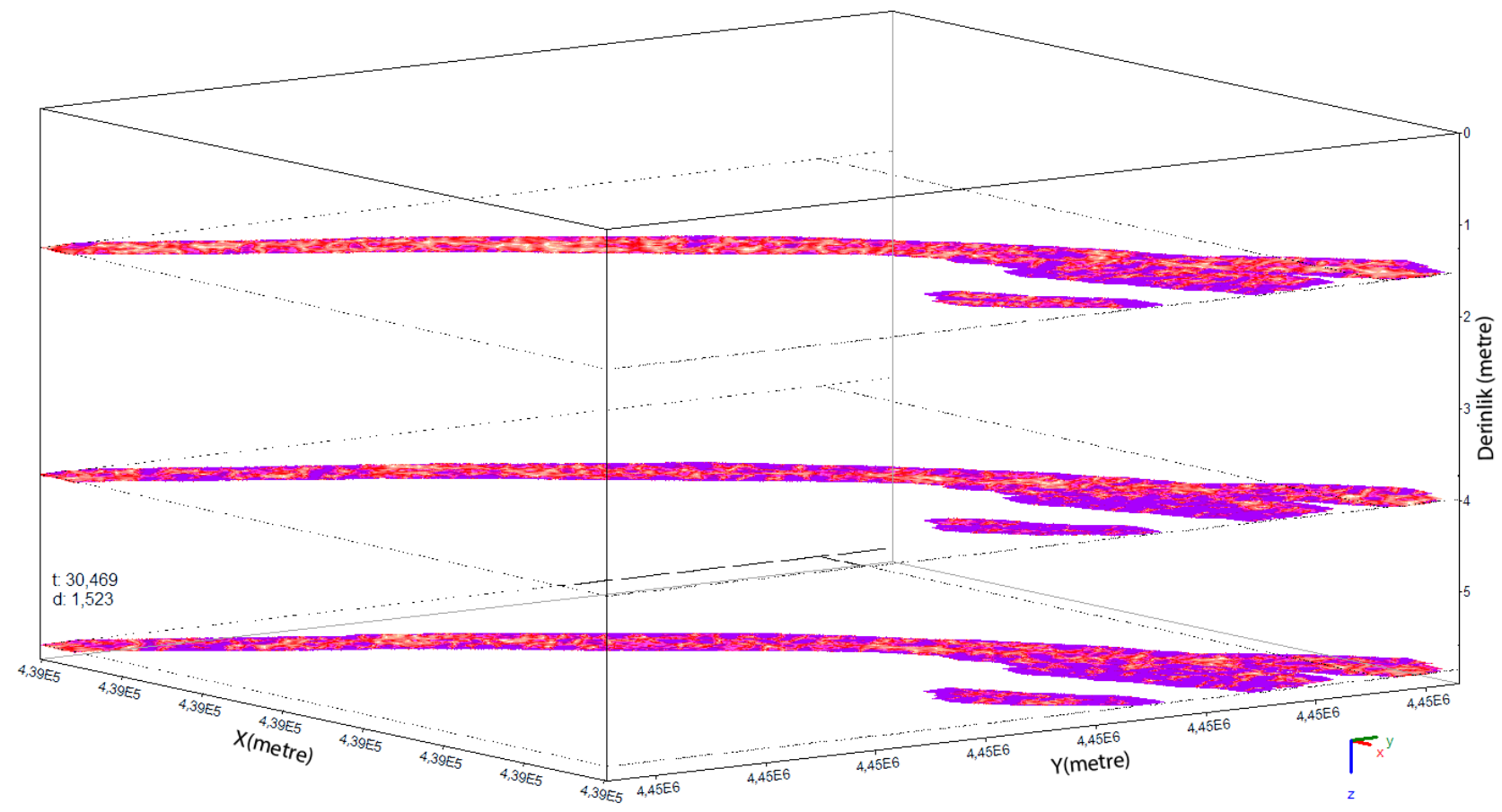

Şekil 12. Lone Pine çalışma alanında elde edilen yeraltı radarına (GPR) ait verilerin derinlik kesitlerinin gösterimi (koyu renkli alanlar belirtilere karşıllk gelmektedir). 


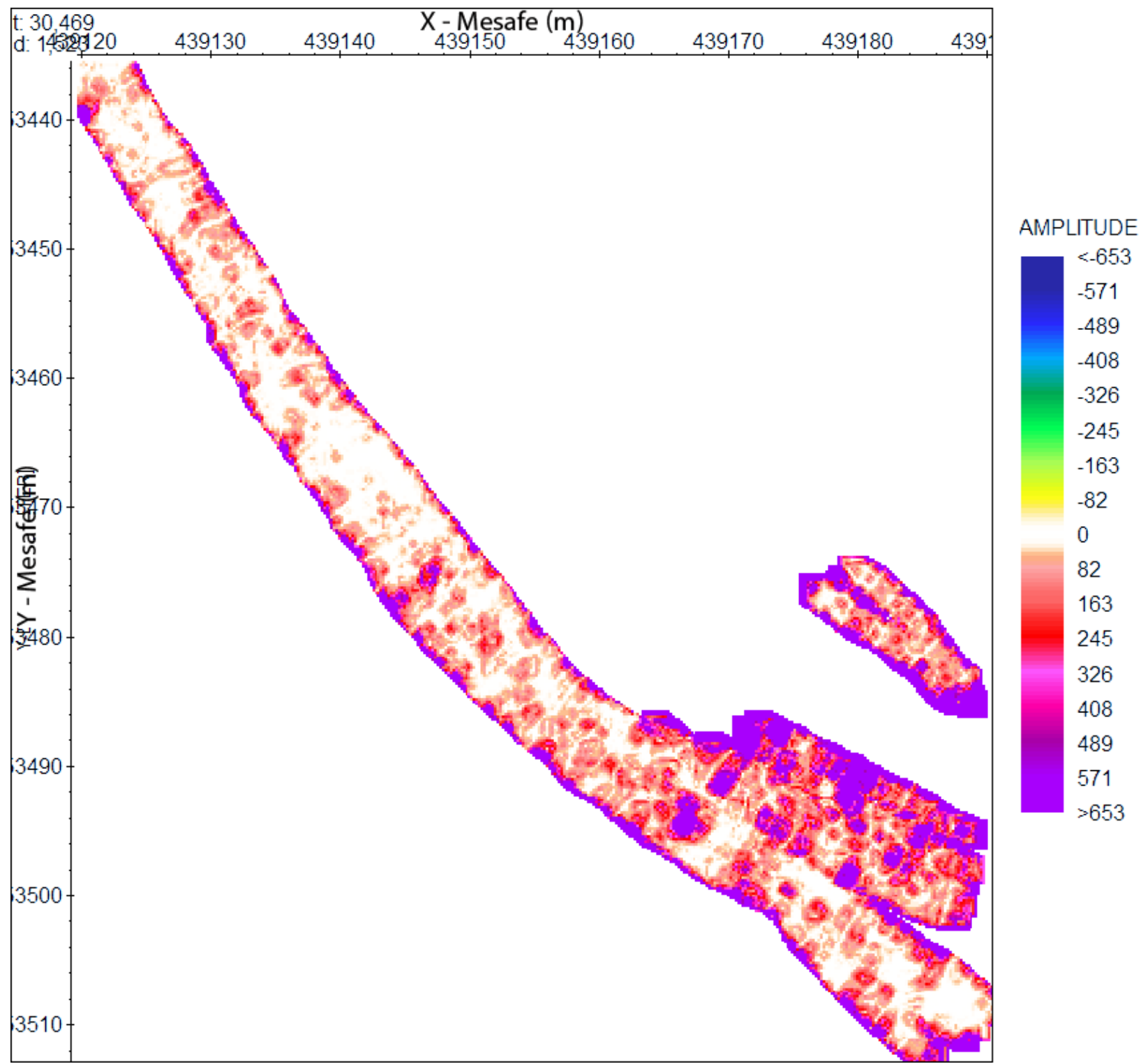

Şekil 13. Lone Pine çalışma alanında elde edilen yeraltı radarına (GPR) ait verilerin en iyi derinlik olan 150 $\mathrm{cm}$ derinlik gösterimi (koyu renkli alanlar belirtilere karşıllk gelmektedir). 


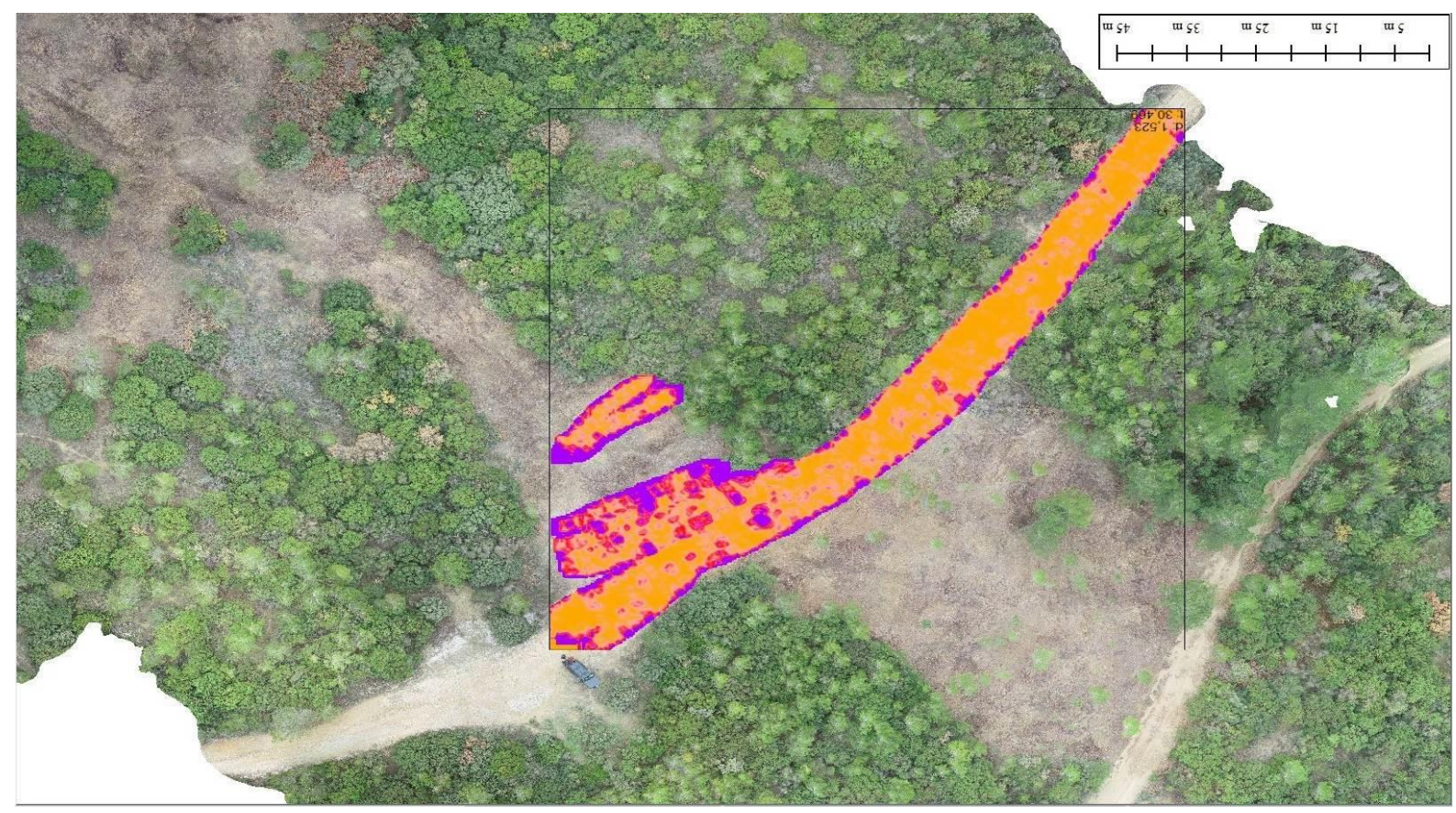

Şekil 14. Lone Pine çalışma alanında elde edilen belirtinin $150 \mathrm{~cm}$ derinde ortofoto üzerinde gösterimi (koyu renkli alanlar belirtilere karşılık gelmektedir).

Lone Pine olarak adlandırılan bölgede yapılan çalışmalar siperlerin haberleşmesinde kullanıldığı düşünülen tünel yapılarının yerlerinin araştırılmasına yönelik gerçekleştirilmiştir. Bu doğrultuda bölgede yaklaşık 1100 $\mathrm{m}^{2}$ 'lik bir alanda ölçüm gerçekleştirilmiştir (Şekil 5c). Saha koşulları nedeni ile (yüksek eğim ve bitki örtüsü) daha geniş bölgelerin ölçümleri yapılamamıştır. Buna rağmen tünel yapısı olduğu düşünülen yapılar $150 \mathrm{~cm}$ derinlikte belirlenmiştir (Șekil 15). 


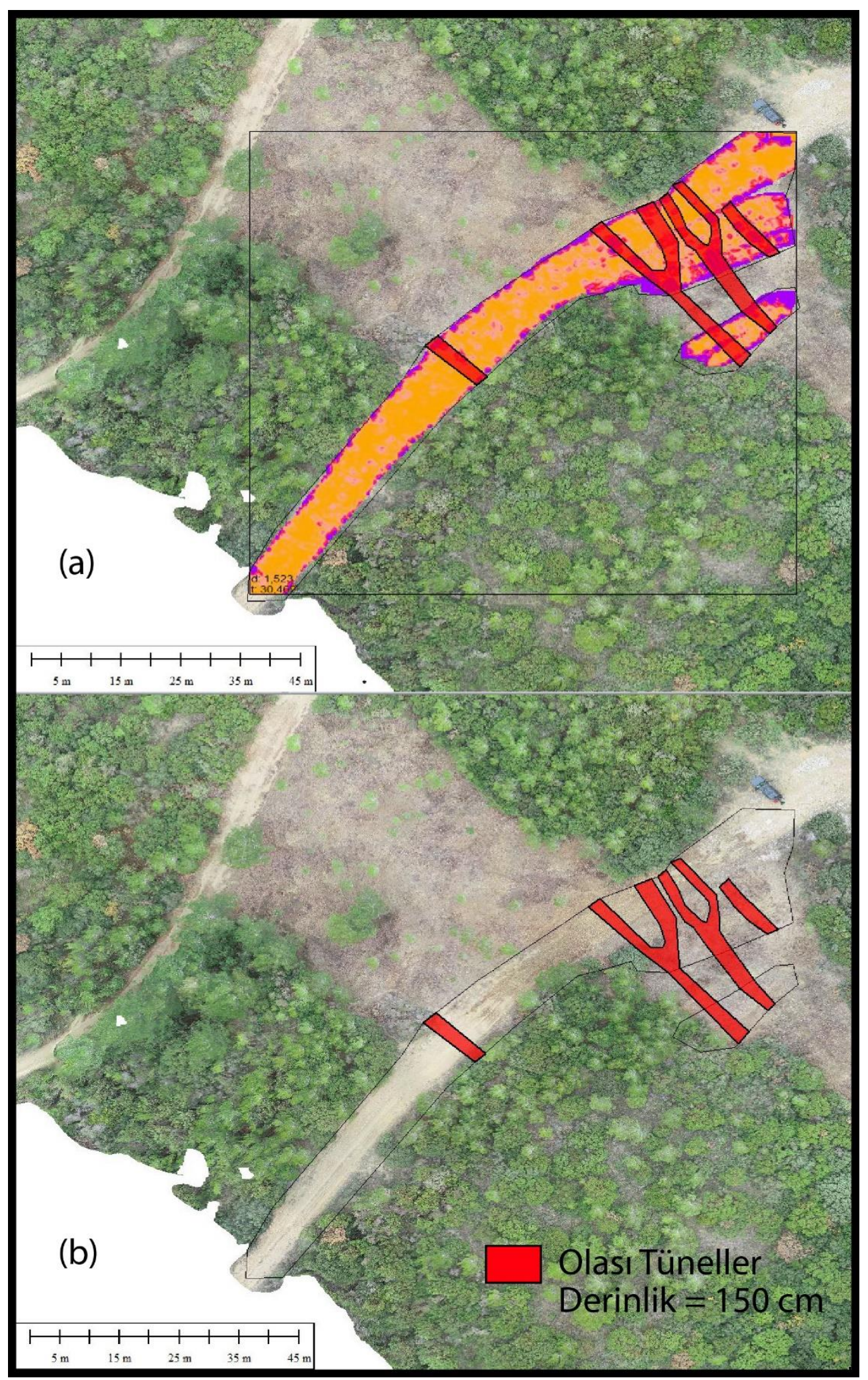

Şekil 15. Lone Pine ölçüm bölgesinde elde edilen sonuçların gösterimi. (a). Yeraltı Radarı (GPR) verileri üzerine belirtilerin yerleştirilmiş görüntüsü. (b) Belirlenen bulgunun ortofoto üzerinde gösterimi. 


\section{Sonuçlar}

Proje sürecinde belirlenen iki farklı çalışma bölgesinde de sonuçlara ulaşılmıştır. Elde edilen sonuçlar daha önceki bilgilere katkı sağlamakla beraber tarihin önemli bir yerini tutan Çanakkale savaşlarının geçtiği bu alanlarda bilinmeyenlere 1şık tutulmuştur. Çalışma genel olarak tüm alanlarda İHA görüntüleri ile elde edilen sayısal yükseklik modeli ve ortofotolar üzerinden yapılan yer belirleme işlemleri ile başlamıştır. İHA uçuşları sayesinde gözle yerden belirlenemeyen yapısal birçok unsur (siper, çukur vb.) modellerde belirlenmiştir. Aynı zamanda yüksek hassasiyetli GPS ile uygulanan yeraltı radarı (GPR) ölçümlerinde de altlık olarak kullanılmıştır. Şahindere Şehitliği çevresinde yapılan çalışmalar ile ölçüm yapılan her alanda "Olası Şehitlik" diye tanımlanabilecek belirtiler yaklaşık $240 \mathrm{~cm}$ derinlikte karşımıza çıkmıştır. Lone Pine olarak adlandırılan bölgede yapılan çalışmalarda ise siperlerin haberleşmesinde kullanıldığı düşünülen tünel yapılarının yerlerinin araştırılmasına yönelik gerçekleştirilmiştir. Bunun sonucunda ise, tünel yapısı olduğu düşünülen yapılar 150 cm derinlikte belirlenmiştir. Çanakkale savaşlarını geçti bölge olan Gelibolu Yarımadası sınırları içerisinde gerçekleştirilen yüksek hassasiyetli Jeofizik ve uzaktan algılama çalışmaları sonucunda daha önce hakkında bilgi az ya da olmayan konulara 1şık tutulmuştur. Proje kapsamında alanın genişliği nedeni ile sadece 2 farklı lokasyonda gerçekleştirilen çalışmalar hedeflenen amaca ulaşmıştır. Koordineli olarak multi-disipliner yürütülen bu çalışmanın devamı olacak çalışmalarda, bu çalışmanın izinde seçilecek yeni alanlar araştırılarak daha fazla bilinmeyene 1şık tutmak mümkün olacaktır.

\section{Teşekkür}

Bu çalışma, FBA-2018-2485 numaralı ÇOMÜ-BAP projesi ile desteklenmiştir. Desteklerinden dolay1 Çanakkale Onsekiz Mart Üniversitesi, Bilimsel Araştırma Projeleri Koordinasyon Birimi'ne teşekkür ederiz.

\section{Yazar Katkıları}

Cahit Çağlar Yalçıner: Saha çalışmaları ve elde edilen verişlerin işlenip yorumlanması kısmında görev almıştır. Ayrıca makaleyi yazmıştır.

Yunus Can Kurban: Saha çalışmaları ve elde edilen verilerin işlenip yorumlanması kısmında görev almıştır.

Erdem Gündoğdu: Saha çalışmaları ve elde edilen verilerin işlenip yorumlanması kısmında görev almıştır.

Mehmet Ali Yücel: Saha çalışmaları ve elde edilen verilerin işlenip yorumlanması kısmında görev almıştır.

\section{Çıkar Çatışması}

Yazarlar çıkar çatışması bildirmemişlerdir.

\section{Kaynaklar}

Annan, A.P., Waller, W.M., Strangway, D.W., Rossiter, J.R., Redman, J.D., \& Watts, R.D. (1975). The electromagnetic response of a low-loss, 2-layer, dielectric earth for horizontal electric dipole excitation. Geophysics, 40(2), 285-298. https://doi.org/10.1190/1.1440525

Annan, A.P., \& Cosway, S.W. (1992). Ground Penetrating Radar Survey Design. 5th EEGS Symposium on the Application of Geophysics to Engineering and Environmental Problems.

Büyüksaraç, A., Bektaş, O., Tulunay, E., \& Ateş, A. (2013). Identification of buried archaeological substances using derivatives of magnetic anomalies in Nif (olympos) Mountain, West Anatolia, Mediterranean Archaeology and Archaeometry, 13(1), 1-8. http://maajournal.com/Issues/2013/Vol13-1/FullTextBuyua2.pdf

Büyüksaraç, A., Sayılır, B., Yalçıner C.Ç., Bektaş, Ö., Kurban, Y. C., \& Topçu, M. İ. (2014). Geophysical Investigation of Buried Cannons in Kumkale (dardanelles), Turkey. Mediterranean Archaeology and Archaeometry, 14(1), 291-299. DOI:10.13140/RG.2.1.4663.1764

Conyers, L. B. (2004). Ground-penetrating Radar for Archaeology. Altamira Press, Walnut Creek, California. 
Daniels, D. J., 2004. Ground Penetrating Radar 2nd Edition, published by the Iee Radar, Sonar, Navigation and Avionics Series, London, United Kingdom.

Gil, E., Mas, Á., Lerma, C., Torner, M. E., \& Vercher, J. (2019). Non-destructive Techniques Methodologies for the Detection of Ancient Structures under Heritage Buildings, International Journal of Architectural Heritage. https://doi.org/10.1080/15583058.2019.1700320

Johnston, B., Ruffell, A., McKinley, J., \& Warke, P. (2018). Detecting voids within a historical building facade: A comparative study of three high frequency GPR antenna, Journal of Cultural Heritage, 32, 117-123. https://doi.org/10.1016/j.culher.2018.02.003

Kanli, A.İ., Taller, G., Nagy, P., Tildy, P., Pronay, Z., \& Toros, E. (2015). GPR survey for reinforcement of historical heritage construction at fire tower of Sopron. Journal of Applied Geophysics. Volume. 112, 79-90. https://doi.org/10.1016/j.jappgeo.2014.11.005

Leucci, G., Masini, N., Persico, R., \& Soldovieri, F. (2011). GPR and sonic tomography for structural restoration: the case of the cathedral of Tricarico, Journal of Geophysics and Engineering, 8, 76-92.

Leucci, G., Masini, N., \& Persico, R. (2012). Time-frequency analysis of GPR data to investigate the damage of monumental buildings, Journal of Geophysics and Engineering, 9, 81-91. https://doi.org/10.1088/1742-2132/9/4/S81

Martínez-Garrido, M. I., Fort, R., Gómez-Heras, M., Valles-Iriso, J., \& Varas-Muriel, M. J. (2018). A comprehensive study for moisture control in cultural heritage using non-destructive techniques, Journal of Applied Geophysics, 155, 36-52. https://doi.org/10.1016/j.jappgeo.2018.03.008

Ming-Chih, L., Yu-Ming, K., Kun-Fa, L., \& Hui-Chi, H. (2009). A study on the technologies for detecting underground water level and processing image, International Journal of Applied Science and Engineering, 7(1), 61-68.

Moropoulou, A., Labropoulos, K., Delegou, E.T., Karoglou, M., \& Bakolas, A. (2013). Non-destructive techniques as a tool for the protection of built cultural heritage, Construction and Building Materials, 48,1222-1239. https://doi.org/10.1016/j.conbuildmat.2013.03.044

Persico, R., Ciminale, M., \& Matera, L. (2014). A new reconfigurable stepped frequency GPR system, possi bilities and issues; applications to two different cultural heritage resources, Near Surface Geophysics, 12, 793-801. https://doi.org/10.3997/1873-0604.2014035

Yalçıner, C. Ç., Bano, M., Kadıglu, M., Karabacak, V., Meghraoui, M., \& Altunel, E. (2009). New temple discovery at the archaeological site of Nysa (western turkey) using gpr method, Journal of Archaeological Science, 36(8), 1680-1689. https://doi.org/10.1016/j.jas.2008.12.016.

Yalçıner, C. Ç. (2012). 2-D and 3-D Diffraction Stack Migration Method to Detect Clandestine Cemetery Using GPR: A Case Study in Çanakkale (Turkey), Mediterranean Archaeology and Archaeometry, 12, 123-130. http://maajournal.com/Issues/2012/pdf/Full7.pdf

Yalçıner, C. Ç., Kurban, Y. C., \& Altunel, E. (2017). Research using GPR into the cause of cracks and depressions in the floor of the gallery of Hagia Sophia Museum. Construction and Building Materials. 139, 458-466. https://doi.org/10.1016/j.conbuildmat.2017.02.036

Yalçıner, C. Ç. Büyüksaraç, A., \& Kurban, Y.C. (2019). Non-destructive damage analysis in Kariye (Chora) Museum as a cultural heritage building. Journal of Applied Geophysics, 171, 103874. https://doi.org/10.1016/j.jappgeo.2019.103874

Yücel, M. A., Yücel, D. S., Yalçıner, C. C. ve Yılmaz, D. (2018). 3D Modelling Of Historical Remains Using Unmanned Aerial Vehicle, A Case Study: Gallipoli Peninsula. XXVIII International Symposium on Modern Technologies, Education and Professional Practice in Geodesy and Related Field, Sofia, Bulgaria, 8-9 November 2018, 101-107. 